\title{
Slik kan sykepleiere forebygge \\ lungekomplikasjoner
}

Mobilisering og smertelindring fremstår som de viktigste tiltakene intensivsykepleieren kan bidra med for å forebygge postoperative lungekomplikasjoner.

\section{Elin Riis}

Intensivsykepleier

Postoperativ avdeling, Oslo universitetssykehus, Aker

Hege Jordet

Intensivsykepleier

Postoperativ avdeling, Oslo universitetssykehus, Aker

Respirasjon

Forebygging

Intensivsykepleie

NSFLIS

Sykepleien 2018106 (65445) (e-65445)

DOI: 10.4220/Sykepleiens.2018.65445

\section{Hovedbudskap}

Postoperative lungekomplikasjoner opptrer ofte hos pasienter som er innlagt på sykehus, og er en av hovedårsakene til sykelighet og $\mathrm{d} \varnothing \mathrm{d}$. Intensivsykepleieren har en viktig rolle ved å kunne forebygge og behandle lungekomplikasjoner. Intervensjoner som smertelindring, mobilisering og pusteteknikker/øvelser belyses i denne artikkelen. 
Postoperative lungekomplikasjoner defineres som

«postoperativ respiratorisk funksjonsnedsettelse» som er av

klinisk betydning og kan påvirke det kliniske forløpet negativt

(1). Tilstanden kan opptre som atelektase (tap av

lungevolum), infeksjon som pneumoni/bronkitt,

sekretstagnasjon/opphopning, bronkospasme, eller forverring av underliggende kronisk lungesykdom.

Forskning viser at det er flere faktorer som $\varnothing$ ker risikoen for utvikling av lungekomplikasjoner. De viktigste er: kirurgi i $\varnothing$ vre abdomen/thoraks, Øyeblikkelig hjelp-kirurgi, kirurgi med varighet over tre timer, alder over 65 år, koronarsykdom, kronisk obstruktiv lungesykdom, funksjonsnedsettelse og pågående $\varnothing v r e$ luftveisinfeksjon (2).

\section{Ulik praksis}

Oslo universitetssykehus har utarbeidet en kunnskapsbasert fagprosedyre for sykepleiere: Lungekomplikasjoner - tiltak for forebygging postoperativt (1). Til tross for retningslinjer erfarer vi at det forekommer ulik praksis, spesielt med hensyn til bruk av hjelpemidler som PEP-fløyte (munnstykke med utskiftbar ventil for å endre motstand) og pustepose (pose med ventil i enden for å regulere motstand).

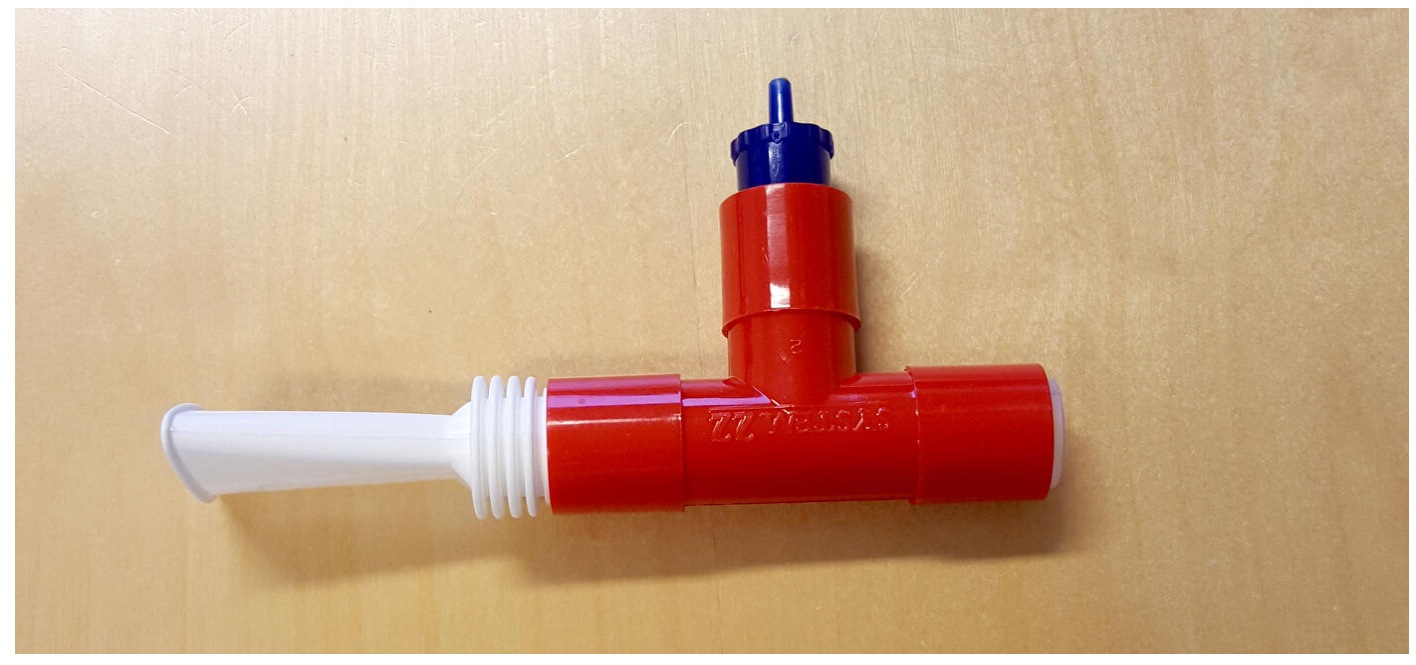

HJELPEMIDDEL: PEP-fløyte er et munnstykke med utskiftbar ventil for å endre pustemotstand. Foto: Elin Riis 


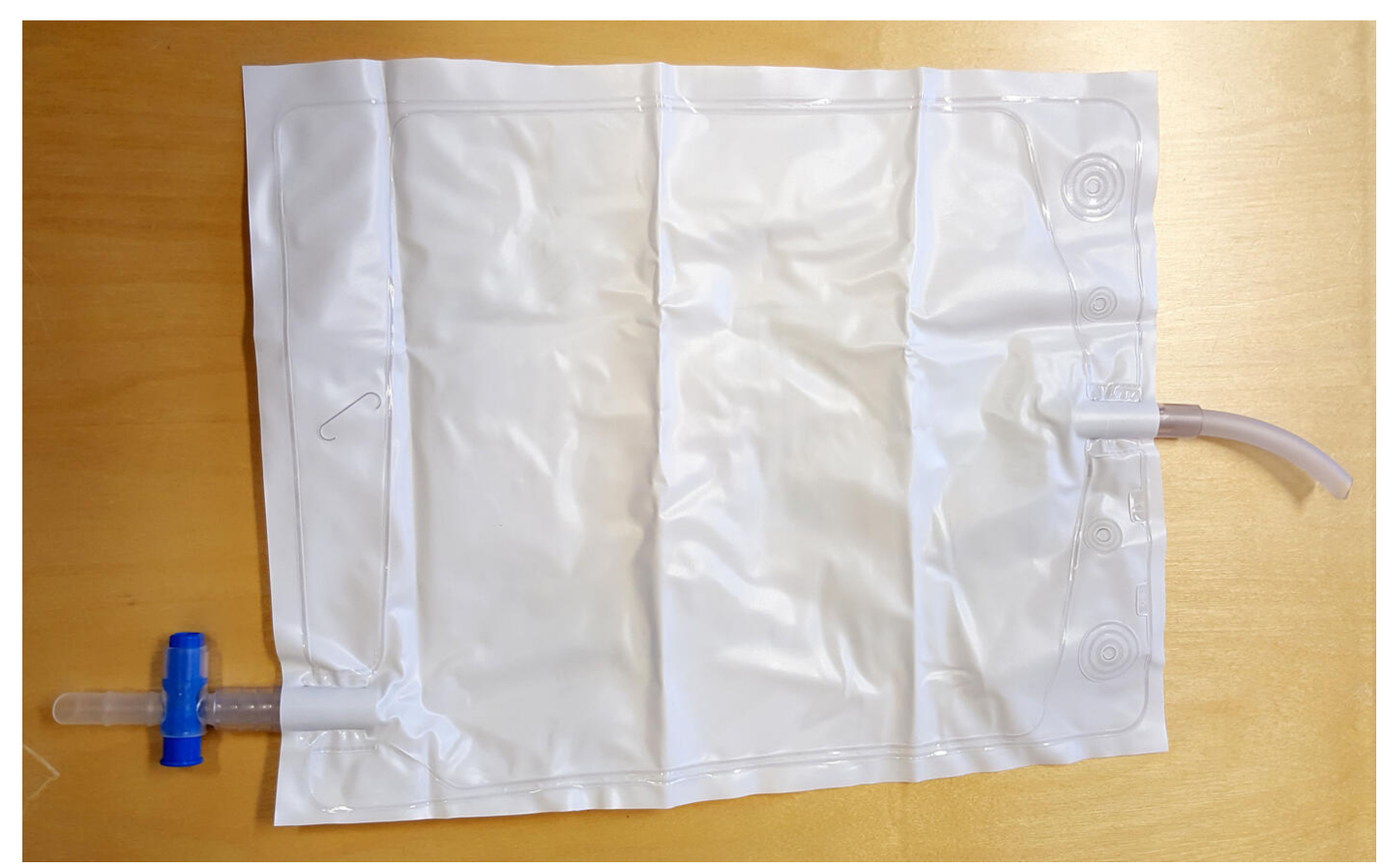

HJELPEMIDDEL: Pustepose med ventil i enden for å regulere motstand. Foto: Elin Riis

Vi kontaktet åtte postoperative avdelinger i Norge for å få en oversikt over hvilke hjelpemidler som blir brukt. På seks av åtte avdelinger brukes PEP-fløyte, og ved to avdelinger brukes både pustepose og PEP-fløyte. Hensikten med denne artikkelen er å formidle kunnskap om hvordan intensivsykepleieren kan forebygge og behandle postoperative lungekomplikasjoner. Respiratorbehandling, noninvasiv (NIV) maskebehandling og high flow-behandling blir ikke omtalt.

\section{Metode}

Artikkelen tar utgangspunkt i en litteraturstudie. Søk ble gjennomført i «Up-to-date», «PubMed», «Cinahl», «Medline» og «Chochrane» i 2013 og 2014. Nytt søk ble gjort høsten 2017. Følgende s $\varnothing$ keord er brukt: «Postoperative lung complications», «mobilisation», «pep-mask», «positioning» og «postoperative breathing exercisis». Ordene ble benyttet hver for seg og i ulike kombinasjoner. Søket ble begrenset til artikler fra 2000 til 2018.

\section{Smertelindring}

Smerte er subjektivt, og derfor er det vanskelig å finne objektive måleinstrumenter (4). A benytte smerteskalaer kan være effektivt, men det vil likevel gi et Øyeblikksbilde og er avhengig av god kommunikasjon med pasienten. OUS' retningslinje for sykepleiere (1) anbefaler Numeric Rating Scale (NRS) to-tre. Målet er at pasienten opplever smertelindring som gjør det mulig å puste dypt, hoste og mobilisere. 
Vi erfarer at noen pasienter angir NRS over tre, men likevel opplever god smertelindring. Å føle seg trygg kan også redusere smerteopplevelsen til pasienten. Bruk av mekanisk

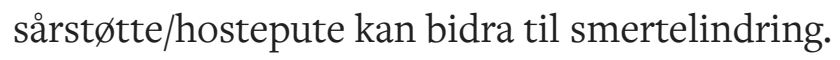

\section{Tverrfaglig smertebehandling}

Adekvat postoperativ smertelindring kan bidra til å minimalisere postoperative lungekomplikasjoner ved å sørge for en tidligere mobilisering og forbedre pasientens mulighet til å puste dypt (2). Dette er spesielt viktig etter thoraks- og $\varnothing$ vre abdominal kirurgi, som innebærer store kirurgiske snitt og langvarig anestesi. Studier har vist at alle pasienter uavhengig av alder og sykdom - får atelektase etter bare et par minutters narkose. Men desto lenger narkose, desto mer lungepåvirkning (3).

\section{$\equiv$ ¿Dersom smertebehandlingen skal være vellykket, må den være tverrfaglig.»}

Forskning viser at sykepleiere underslår pasientens angivelse av smerter $(5,6)$. Vurdering av smerte krever lang erfaring og kunnskap, men også et godt tverrfaglig samarbeid mellom leger og sykepleiere. Dersom smertebehandlingen skal være vellykket, må den være tverrfaglig, og de ulike yrkesgrupper må være faglig oppdaterte og samarbeide slik at pasientene mottar den beste smertebehandlingen» (6). Faglig oppdatering bidrar til at sykepleiere og leger får kunnskap om nye behandlingsmetoder og medikamenter til bruk i smertebehandling.

\section{Epidural vs. opioider}

Mobilisering med kontinuerlig epidural smertelindring kan forbedre lungefunksjonen postoperativt (7). Vår erfaring st $\varnothing$ tter denne oppfatningen, da vi ser at pasienter etter $\varnothing$ vre abdominal kirurgi har bedre muligheter til å puste dypt, hoste og bli mobilisert med epidural smertelindring. Flere studier viser at epidural er å foretrekke fremfor parenterale opioider $(2,8)$. Sterke smerter i forbindelse med mobilisering ut av seng og mobilisering av slim ved kraftig hoste, kan være vanskelig å løse med opioider uten at det forårsaker uønskete effekter (4). 
De uønskete effektene kan være trøtthet, luftsmerter og ventrikkelretensjon. Av den grunn kan det være vanskelig for pasientene å klare å puste dypt, hoste kraftig og samarbeide i forbindelse med mobilisering. Dersom epidural smertelindring ikke er mulig, eller operasjonstypen ikke krever epidural smertelindring, er det en fordel at den perorale smertelindringen starter preoperativt, slik at pasienten har nytte av den postoperativt. Vi erfarer at innføring av premedikasjon med opioider, gjør pasientene mer våkne og bedre smertelindret i det postoperative forløpet.

\section{Tidlig mobilisering}

Mobilisering som inkluderer oppreist stilling bedrer lungefunksjonen ved å få strekk på lungene og er derfor fordelaktig tidlig i den postoperative fasen $(7,9,10)$. En studie av pasienter som har gjennomgått høyrisiko kirurgi som aortakirurgi - viste at pasienter som ble tidlig mobilisert utviklet færre postoperative lungekomplikasjoner.

Forekomsten av postoperative lungekomplikasjoner $\varnothing$ ker for hver dag man utsetter mobilisering (2). Mobilisering til sittende/stående/gående posisjon er ifølge Nielsen og medarbeidere den beste intervensjonen for å forebygge lungekomplikasjoner. Leieendring fra rygg- til sideleie viser begrenset effekt på lungefunksjonen (7).

\section{$\equiv$ «Pasienter som opereres med gastric bypass laparoskopisk, skal mobiliseres innen én time etter ankomst.»}

Vi har erfaring med å mobilisere pasienten tidlig postoperativt. Pasienter som opereres med gastric bypass laparoskopisk, skal mobiliseres innen én time etter ankomst på postoperativ avdeling. For denne pasientgruppen er det laget et standardisert forløp, der pasienten på forhånd er informert om mobiliseringen. Det kan tenkes at thyreiodektomier og laparoskopiske prostatektomier kunne ha nytte av et tilsvarende opplegg. Intensivsykepleieren må i hvert tilfelle vurdere om pasienten kan mobiliseres opp på sengekant/til stående, eller om snuing fra side til side er tilstrekkelig i pasientens nåværende situasjon. 
OUS’ retningslinje anbefaler mobilisering på

operasjonsdagen, dersom den kliniske tilstand og det

kirurgiske inngrepet tillater det. Unntaket er restriksjoner

knyttet til det enkelte inngrepet (1). Fysioterapeut kan

involveres i forbindelse med mobilisering. På den måten kan

pasienten dra nytte av tverrfaglig ekspertise.

\section{Pusteteknikker og øvelser}

Puste- og hosteøvelser, fysioterapi og behandling med positivt ekspirasjonstrykk (PEP) - som oppnås ved bruk av enkle hjelpemidler hvor man blåser ut mot en motstand i en maske eller et munnstykke - er tiltak som kan redusere atelektase og pneumoni $(1,11,12)$. Smetana (2) konkluderer med at dype pusteøvelser, lungefysioterapi og bruk av hjelpemidler som kontinuerlig luftveisovertrykk CPAP (Continuous Positive Airway Pressure). CPAP er et apparat som blåser luft gjennom en slange med en trykkregulator. Denne kan være med å redusere forekomsten av lungekomplikasjoner.

OUS' retningslinje for sykepleiere (1) anbefaler pusteøvelser som $\varnothing$ ker tidalvolumet (volumet som inspireres eller ekspireres under hvile). Og dersom PEP hjelpemiddel brukes, anbefales ti blås, tre ganger per våkne time. Retningslinjen forutsetter at intensivsykepleieren har spesifikke kunnskaper om hjelpemidlene og bruken av disse. Feil bruk av PEPhjelpemiddel og pustepose, som for eksempel at pasienten ligger flatt i senga eller blåser for hardt, kan føre til at pasienten pådrar seg lungekomplikasjoner postoperativt. Dette understreker hvor viktig samarbeidet mellom fysioterapeuter, sykepleiere og leger er, da man drar nytte av hverandres erfaring og kunnskap om pusteøvelser.

\section{Lungekomplikasjoner}

Lungefunksjonen til pasienten før operasjonen har stor betydning for det postoperative forløpet. Smetana vektlegger derfor betydningen av å undervise og informere pasienten om lungeekspanderende teknikker preoperativt (2).

Forskning viser at forekomsten av lungekomplikasjoner er lavere blant pasienter som mottar preoperativ forberedelse, som for eksempel lungefysioterapi (2). Gastric bypasspasienter mottar preoperativ informasjon om postoperative pusteøvelser. Vi opplever at de er forberedt på det postoperative forløpet og kan samarbeide bedre. I OUS sin prosedyre for fysioterapi står det: «Prosedyren skal sikre at pasientene får adekvat og kunnskapsbasert preoperativ og postoperativ fysioterapi» (12). 


\section{«Smertelindring og mobilisering må til for at pasientene skal dra nytte av pusteøvelsene.»}

Det hadde vært fordelaktig for høyrisikopasienter at forebygging av lungekomplikasjoner starter før operasjonen. Pasienter som gjennomgår obesitaskirurgi har høyere risiko for å utvikle lungekomplikasjoner. Pusteøvelser for denne pasientgruppen er ikke bevist å være fordelaktig, selv om lungefunksjonen ble betraktelig forbedret ved at tidalvolumet $\varnothing k t e$ (13). Vi ser i praksis at bruk av pustepose postoperativt bidrar til å legge vekt på dype pust, men erfarer at god smertelindring og mobilisering må til for at pasientene skal dra nytte av pusteøvelsene.

\section{Bruk av pustepose}

På vår avdeling har vi lang erfaring med å gi pustepose til pasienter med inngrep i øvre abdomen og laparoskopiske operasjoner, som for eksempel gastric bypass og prostatektomier. Fysioterapeutene ved avdelingen har introdusert PEP-hjelpemiddel og pustepose som sykepleierne hjelper pasientene å bruke. Fysioterapeuten er ikke tilgjengelig hele døgnet, og derfor er det viktig at intensivsykepleieren kan anvende sin kunnskap. Hensikten med åpningen i posen er at den skal bremse utpusten slik at utpusten blir passe lang og med passe kraft.

I våre litteraturs $\varnothing \mathrm{k}$ fant vi ingen spesifikk forskning om bruk av pusteposer som støtter best praksis. Sykepleieren gjør vurderinger av pasienten i hver enkelt situasjon og vurderingene avgjør graden av luftmotstand som velges. Sykepleiere stiller åpningen på pusteposen ulikt, og vi instruerer og informerer pasienter forskjellig. I tillegg er det ikke mulig å måle den motstanden pasienten blåser mot.

\section{Valg av hjelpemidler}

Valg av tidspunkt for bruk av hjelpemidler er også en viktig vurdering. Pasienten må være motivert og våken. En pasient som har smerter og som ligger i flatt sengeleie, får liten effekt både av PEP-fløyte og pustepose. Høy sittestilling og smertelindring er essensielt for at pusteøvelser kan utføres med mest effekt. 
Forskning viser at lungeekspanderende teknikker som $\varnothing$ ker tidalvolumet (volumet som inspireres eller ekspireres under hvile) reduserer alle typer postoperative lungekomplikasjoner, sammenliknet med ingen intervensjoner. Vi finner likevel ikke at enkelte lungeekspanderende teknikker er mer fordelaktig fremfor andre $(8,14)$ Conde og Lawrence oppsummerer det slik: «we don't know which is the most effective lung expansion technique to use» (14).

Smetana (2) konkluderer derimot med at de postoperative tiltakene som definitivt er fordelaktig er dype pusteøvelser og incentive spirometri.

\section{Dype pusteøvelser}

Insentiv spirometri brukes ikke i Skandinavia, men pusteøvelser med PEP gis ofte rutinemessig til pasienter som gjennomgår kirurgi. Det er få vitenskapelige bevis for at PEPbehandling er bedre enn andre fysioterapi-pusteteknikker for pasienter som gjennomgår abdominal eller thorakal kirurgi. I våre $s \varnothing \mathrm{k}$ i de ulike databasene fant vi ikke studier som unders $\varnothing$ ker PEP-effekten i forhold til placebo eller fysioterapibehandling.

Det man kan si er at optimal smertelindring og instruksjon om hvordan og når man skal utføre pusteøvelser er avgjørende. Dype pusteøvelser kan vise seg å være minst like effektivt som PEP-fløyte etter abdominal og thorakal kirurgi, men hittil har ikke dette vært unders $\varnothing \mathrm{kt}$ tilstrekkelig $(15,16)$. M. Antonsson og medarbeidere hevder følgende: «Det finnes i dag ingen konsensus angående behandlingsmetodernas duration och intensitet» (17).

\section{Erfaring rundt lungekomplikasjoner}

De ulike intensivavdelinger og sengeposters kjennskap til prosedyren «Forebygging av lungekomplikasjoner postoperativ» er varierende. Antonsson og medarbeidere (17) som har utarbeidet svenske retningslinjer for «andningsvårdande behandling» skriver: « I väntan på mer forskning får klinisk erfarenhet vara vägledande». Det er derfor viktig å jobbe tverrfaglig med fysioterapeut og anestesilege for å dra nytte av hverandres erfaring og komme fram til løsninger som er til beste for den enkelte pasient. 
Fysioterapeuters erfaring med pusteøvelser og hjelpemidler kan formidles til sykepleierne slik at hjelpemidler som PEPfløyte ikke bare blir gitt til pasienten, men at sykepleierne påser at hjelpemidlene også blir brukt riktig. Det handler ikke om å erstatte enkelte profesjoner, men å dra nytte av hverandre. Erfarne sykepleiere må likeledes formidle sin kunnskap og erfaring til nye sykepleiere. God opplæring og oppfølging på avdelingen er grunnleggende for kunnskapsbasert praksis og vil utgjøre en forskjell i arbeidet med å forebygge lungekomplikasjoner postoperativt.

\section{Forebygging av lungekomplikasjoner}

Kompetanse kan defineres som kunnskap, ferdigheter og holdninger (18). Kravet til kompetanse i intensivsykepleiefaget endres over tid, og stiller kontinuerlig krav til faglig oppdatering. Pasienter forventer å få pleie og behandling av god kvalitet, unngå komplikasjoner og å bli møtt med respekt. Samfunnet krever at yrkesutøvelsen skal være basert på forskning og fagutvikling, ikke bare sedvane og tradisjon. Kompetansen, miljøet og søkelyset på forebyggingen av postoperative lungekomplikasjoner kan variere.

Utfordringer i den praktiske hverdagen på intensivavdelingen kan påvirke forebyggingen av lungekomplikasjoner. Det kan dreie seg om lav bemanning, ulik kompetansesammensetning hos sykepleiere og forskjellig kvalitet på samarbeidet med andre faggrupper.

\section{$\equiv$ ¿Kunnskapsbaserte beslutninger er én del av god sykepleie.»}

Intensivsykepleierens kompetanse vil gjenspeile hvilke prioriteringer hun/han gjør, og prioriteringene kan avgjøre pasientens helbred. Intensivsykepleieren har kompetanse som gjør at vedkommende kan være «i forkant» av ulike situasjoner, kontra sykepleieren med mindre erfaring som forholder seg til situasjonen «her og nå». Kjernen i kunnskapsbasert praksis er at sykepleieren har den nødvendige kompetansen til å ta velinformerte beslutninger. Kunnskapsbaserte beslutninger er én del av god sykepleie (18). 


\section{Forskningsbasert kunnskap}

OUS har, som nevnt, utarbeidet en kunnskapsbasert klinisk retningslinje for sykepleiere (1), og en prosedyre for fysioterapeuter (12). Retningslinjene er basert på forskning og erfaring og skal bidra til å forebygge og begrense postoperative lungekomplikasjoner hos selvpustende pasienter innlagt ved postoperative-, intensiv- og intermediæravdelinger. Disse bidrar til å sikre at pasienter får samme behandling, uavhengig av hvilken avdeling de er innlagt på. Hvor kjent retningslinjene er, og i hvilken grad de blir brukt, vil være av betydning for hvor lik behandlingen blir. Vår erfaring er at pasientens progresjon i å gjenvinne sitt eget omsorgsnivå øker, når man har en individuell plan som følges opp.

Den forskningsbaserte kunnskapen skal informere praksis, men ikke diktere denne. Forskningen viser til hvordan forebygging av postoperative lungekomplikasjoner kan/bør gjøres, men intensivsykepleieren må i tillegg bruke sin erfaringsbaserte kunnskap. Det bør likevel finnes en god begrunnelse for hvorfor man ikke følger en anbefaling i retningslinjene som bygger på en sterk evidens (11).

\section{Oppsummering}

Forebygging av postoperative lungekomplikasjoner i en postoperativ avdeling er et kontinuerlig arbeid. Arbeidet krever - i tillegg til å legge vekt på god kompetanse om temaet - tilstrekkelig bemanning, tverrfaglig samarbeid og tilgjengelig utstyr.

Forskning gir ingen entydige svar på hvilken metode/teknikk som er å foretrekke for å forebygge postoperative lungekomplikasjoner. Det finnes for lite forskning på området, og mye av forskningen er gammel. Det er behov for ny forskning om temaet.

Mobilisering og smertelindring fremstår som de viktigste tiltakene intensivsykepleieren kan bidra med, for å forebygge postoperative lungekomplikasjoner. Om en velger pep-fløyte eller pustepose er ikke like viktig. Effekten av å bruke pustepose er ikke evidensbasert, men det kan være at man $\varnothing$ ker oppmerksomheten på pasientens respirasjon ved å anvende pustepose, instruere og samhandle med pasienten. Det viktigste er å vite hva man gjør, og begrunne valg av de ulike tiltakene. Mangel på evidens er ikke det samme som mangel på effekt. Et aktivt tverrfaglig fagmiljø, som deler erfaringsbasert kunnskap og oppdaterer seg på forskning, kan bidra til å gjøre valgene enklere. 
Intensivsykepleieren må konsentrere seg om god smertelindring for pasienten og gi instruksjoner om dype pust og betydningen av å hoste. I tillegg må intensivsykepleieren informere pasienten om hvor viktig det er med tidlig postoperativ mobilisering og, ikke minst, legge til rette for det.

Se oppsummering av artikkelen i denne posteren.

\section{Referanser}

1. Gabrielsen AK. Retningslinje postoperative tiltak for forebygging av lungekomplikasjoner - voksne. Nivå 1 prosedyre. Oslo: OUS; 2016 Tilgjengelig fra: http://www.helsebiblioteket.no

2. Smetana G. Strategies to reduce postoperative lung complications. Uptodate 2018. Tilgjengelig fra: https://www.uptodate.com/contents/strategies-to-reducepostoperative-pulmonary-complications-in-adults (nedlastet 30.01.2018).

3. Olsèn MF. Andningsvård efter kirurgi till högriskpatienter - färre komplikationer och snabbare återhämtning. Fysioterapi. 2006;5:38-43.

4. Breivik H, Borchgrevink, PC, Allen SM, Rosseland LA, Romundstad L, Breivik Hals EK, Kvarstein G, Stubhaug A. Assessment of pain. BJA. 2008;101(1):17-24.

5. Peter E, Watt-Watson J. Unrelieved pain: An ethical and epistemological analysis of distrust in patients. CJNR. 2002;34(2):65-80.

6. Leegaard M, Husby Y, Berge AW, Rustøen T. Hvilke kunnskaper trenger sykepleiere for å hjelpe pasienter til å håndtere smerter etter hjertekirurgi? Sykepleien Forskning. 2011;(6):254-61. Tilgjengelig fra: www.sykepleien.no/forskning (nedlastet 01.10. 2017).

7. Nielsen KG, Holte K, Kehlet H. Effects of posture on postoperative pulmonary function. Acta Anaesthesiologica Scand. 2003 november;47(10):1270-5. 
8. Qaseem A, Snow V, Fitterman N, Hornbake ER, Lawrence VA, Smetana GW, Weiss K, Owens DK. Risk assessment for and strategies to reduce perioperative pulmonary complications for patients undergoing noncardiothoracic surgery: A guideline from the American college of physicians. Ann Internal Med. 2006 April; 18;144(8):575-80. Tilgjengelig fra: https://www.ncbi.nlm.nih.gov/pubmed (nedlastet $01.10 .2017)$.

9. MacKay MR, Ellis E, Johnston C. Randomised clinical trial of physiotherapy after open abdominal surgery in high risk patients. Australian Journal of Physioteraphy. 2005;51(3):151-9.

10. Browning L, Denehy L, Scholes R. The quantity of early upright mobilisation performed following upper abdominal surgery is low: An observational study. Australian Journal of Physioteraphy. 2007;53(1):47-52. Tilgjengelig fra:

https://www.ncbi.nlm.nih.gov/pubmed/? term=Browning+L\%2C+Denehy+L\%2C+Scholes+R.+The+qua ntity+of+early+upright+mobilisation+performed+following $+\mathrm{u}$ pper+abdominal+surgery+is+low\%3A+an+observational+study .+Australian+Journal+of+Physioteraphy (nedlastet 01.10.2017).

11. Antonsson M, Olsèn MF, Johannson H, Sandstrøm L, Urell C, Westerdahl E, Wiklund M. Riktlinjer för andningsvårdande behandling innom sjukgymnastik for patienter som gjenomgår buk- och thoraxkirurgi. Svenska Götalandsregionene: Sahlgrenska universitetssjukehuset; 2009;2(33) Tilgjengelig fra:

https://www.regionorebrolan.se/filessv/uso/kliniker_enheter/s jukgymnastik/forskning/resp_kir\%20_slutversion\%20091222 \%20\%282\%29.pdf (nedlastet 01.10.2017).

12. Brautaset K. Oslo universitetssykehus. Fysioterapi for forebygging av postoperative lungekomplikasjoner. OUS; 2012. Tilgjengelig fra: http://www.helsebiblioteket.no/fagprosedyrer/ferdige/lungeko mplikasjoner-postoperative-tiltak-for-forebygging (nedlastet 06.02.2018).

13. Olbers T, Lönroth H, Olsén MF, Lundell L. Laprascopic Gastric Bypass: Development of Technique, Respiratory Function, and Long-Term Outcome. Obesity Surgery. 2003 Juni;(13):364-70. 
14. Conde M, Lawrence V. Postoperative pulmonary infections. BMJ Clin Evid. 2008 September;29. Tilgjengelig fra: https://PubMed.com/ (nedlastet 01.10.2017).

15. Örman J, Westerdahl E. Chest physioteraphy with positive expiratory pressure breathing after abdominal and thoracic surgery: a systematic review. Acta Anaesthesiologica Scand. 2010 Mars;54(3):261-7.

16. Giæver P. Lungesykdommer 3.utg. Oslo:

Universitetsforlaget; 2015 .

17. Antonsson M, Olsén MF, Johansson H, Sandstrøm L, Urell C, Westerdahl E, Wiklund M. Andningsvårdande behandling vid buk- och thoraxkirurgi. Fysioterapi $2010 \mathrm{nr}$. 2:36-40.

18. Nortvedt M, Jamtvedt G, Graverholt B, Nordheim LV, Reinar LM. Jobb kunnskapsbasert-en arbeidsbok for sykepleiere 2.utg. Oslo: Cappelen Damm Akademisk; 2012. 